A.S. Tondare MD, DA, MBbs, A. W. Nadkami MD, DA, MBBS, C.H. Sathe MD, DGO, MBBS, V.B. Dave MS, DA, MBBS

\section{Femoral Neuropathy: A Complication of Lithotomy Position Under Spinal Anaesthesia} REPORT OF THREE CASES
Three patients developed solitary unilateral peripheral femoral neuropathy after vaginal hysterectomy. All were operated under subarachnoid analgesia in the ithotomy position. Straight rod leg supports with swing stirrups were used and the procedures lasted for two and one-half hours. The complication is thought due to the extreme abduction of thighs with external rotation at the hip causing ischaemia of the femoral nerve as it is kinked beneath the tough inguinal ligament. The prognosis was found to be excellent with complete recovery within eight to ten weeks. The complication is prevertable by using lateral thigh supports limiting the degree of abduction.

Key Words

SURGERY; gynaecology, lithotomy position; COMPLICATIONS; femoral neuropathy.
From the Departments of Anaesthesiology and Obstetrics and Gynaecology, Government Mcdical College and Huspital, Aurangabad, Maharashtra State, INDIA.

Address for carrespondence: Dr. A.S. Tondare, D-7, Type-III Quarters, Behind Dean's Bungalow, Medical Campus, AURANGaBaD: 431001 (M.S.) INDIA.
The state of anaesthesia - either regional or general - renders the patient partially or totally insensitive to the usual warming signals of pain from nerve injury. The physician who thus renders patients incapable of protecting themselves assumes the responsibility for their welfare during anaesthesia and recovery. Nat only that, but the anaesthetist as a physician has an ethical responsibility to wam the surgeon of potential nerve injury from positions which involve undue stress, pressure, or forces acting directly or indirectly on neuro-vascular structures.

\section{Report of cases}

\section{Patient 1}

A 45-year-old woman was admitted with uterine prolapse. The medical history was negative. She underwent vaginal hysterectomy under uneventful subarachnoid block with $2 \mathrm{ml}$ of bupivacaine one per cent. The procedure lasted for three hours with the patient in the lithotomy position in swing stirrups on single straight rods. The patient tolerated the procedure well and no surgical complications occurred.

On the third postoperative day the patient complained of numbness and tingling in her left thigh. When she attempted to stand, the left knee buckled, and she lost the self-confidence to walk without assistance. Neurological examination revealed slight weakness of flexion of thigh over pelvis, gross inability to extend the leg at the knee, but there was no loss of hip adduction or abduction. There was marked sensory loss manifested by hypoaesthesia and anaesthesia on the anteromedial 
aspect of the left thigh. The left knee jerk was absent. The right lower extremity was completely normal in all respects. A diagnosis of quadriceps weakness secondary to subarachnoid block was made, but the exact aetiology remained unclear. Therapy was instifuted in the form of aclive and passive quadriceps exercises and within three weeks some motor activity had retumed. The patient was discharged after 21 days with the advice to continue the exercises. Two and one-half months later, no evidence of residual neurological deficit could be found.

\section{Patient 2}

A 50-year-old woman underwent vaginal hysterectomy with anterior and posterior colporhaphy for uterine prolapse with rectocele and cystocele under uneventful subarachnoid block with one per cent bypivacaine. Two days later when she attempted to stand, she found herself unable to bear weight on the right leg. On the third day she noticed numbness and tingling in the right thigh. On neurological examination, she was unable to extend the right leg at the knee, the knee jerk was absent, but there was no loss of hip adduction or abduction. Hypoaesthesia was present on the antero-medial surface of the right thigh. By the eighteenth postoperative day some weakness in extending the right leg still remained. She was discharged with instructions to continue quadriceps exercises and to report after a fortnight. In the fifth postoperative week she reported to hospital with subjective improvement. On neurological examination there was no hypoaesthesia and she was able to extend the right leg at the knee against gravity; the knee jerk was now present.

\section{Patient 3}

A 40-year-old woman was admitted with uterine prolapse and cystocele. She underwent vaginal hysterectomy with anterior colporhaphy under uneventful subarachnoid block with $2 \mathrm{ml}$ of one per cent bupivacaine. She was in the lithotomy position in swing stirrups. On the second day after operation the patient complained of tingling and nurnbness in the left thigh. When she attempted to walk she found it difficult and lost the self-confidence to walk further. On examination, hypoaesthesia was found on the medial aspect of the left thigh and the patellar reflex was sluggish. Active therapy was instituted in the form of active and passive quadriceps exercise and continued for three weeks in hospital. At the time of discharge the patient had only minimum residual sensory loss on the medial aspect of the left thigh and the patellar reflex was active. The patient was able to extend the leg at the knee and was able to walk without assistance.

\section{Discussion}

Any neuropathy after subarachnoid block can easily be blamed on the block unless proven otherwise. Femoral neuropathy was a well-known entity in pelvic operations at a time when self-retaining abdominal retractors were being used routinely, but there has been hardly any mention in the literature of this kind of neuropathy following pelvic operations in the lithotomy position. In our three cases of vaginal hysterectomy the neurological examination showed selective unilateral impairment of femoral nerve conduction in the periphery. The femoral nerve $^{2}$ is the largest branch of the lumbar plexus and arises from the undivided primary rami of $L 2,3$ and 4. Immediately after its formation the nerve penetrates the greater psoas muscle and continues downward within the substance of that muscle. It leaves it at the lower portion of its lateral border where it passes between the psoas and iliacus muscles. It exits from the abdominal cavity just below the inguinal ligament and lateral to the femoral artery. Motor branches to the iliacus muscle are given off within the abdomen.

Below the ligament it divides into several branches to provide the motor supply to the quadriceps muscles of the thigh, the pectineus and sartorius muscles and occasionally to the long adductors. However, there are individual variations in both motor and sensory innervation by the femoral nerve. It is easy to identify the site of a lesion if one is aware that the nerve to the iliopsoas leaves the plexus just after the formation of femoral nerve and hence if the $L 1$ to $L 4$ roots are affected, the function of iliopsoas is impaired along with the muscles innervated by the femoral nerve.

As the intra-abdominal course of the femoral nerve is well protected within the psoas muscle and between the iliacus and psoas, injury to the nerve at these sites is unlikely in vaginal hysterectomy using ribbon retractors. A mere stretch on the nerve due to the lithotomy position, as suggested in a case reported by Roblee ${ }^{1}$ is also not a possibility because to produce nerve damage by this mechanism a force equal to the pull of 32 to $60 \mathrm{~kg}$ is said to be necessary. ${ }^{2}$ Rosenblum ${ }^{2}$ has reviewed the subject 
of femoral neuropathy as a complication of hysterectomy; however, all but one of the 45 reported cases he studied had pelvic operations in the supine position. They did anatomic studies on cadavers and concluded that the aetiology of this neuropathy was prolonged and constant pressure on the greater psoas, usually by intra-abdominal retractor blades, producing ischaemia of the femoral nerve. Selfretaining retractors were often to blame. The type of abdominal incision and thin build of the patient are additional factors to be considered in the causation of this complication. This has also been suggested by Vosburgh and Finn, ${ }^{3}$ and further stressed by Klings. ${ }^{4}$

The intense analgesia and profound muscle relaxation obtained by subarachnoid block make it possible to produce extremes of positioning. The single straight rod with swing stirrups helps to avoid sciatic and peroneal nerve palsies, but allows exaggerated abduction of the thighs with marked external rotation at the hip. This causes the femoral nerve to enter the thigh acutely angulated and twisted beneath the tough and inelastic inguinal ligament leading to compression of its vasa nervosa, thus producing local ischaemia of the nerve trunk.

The duration for which this position is maintained is an important factor because, to our knowledge, use of the same position for perineal operations lasting for less than one and one-half hours is seldom associated with this neuropathy. It appears from a case reported by Rable ${ }^{1}$ and from our cases that a neuropathy can result if the ischaemia exceeds one and one-half hours.

One more factor which helps to increase the abduction of thigh and its extemal rotation, is that surgical assistants often lean against the inner aspect of the thighs.

With the understanding of the pathogenesis, prevention becomes easy. The excessive abduction of the thigh with rotation at hip needs to be prevented by lateral supports to the thighs. ${ }^{1}$ However, lateral thigh supports are not popular with surgeons. The reduced abduction of the thighs is inconvenient to the assisting surgeon, but this must yield to patient safety.

In summary, we present three cases of vaginal hysterectomy under subarachnoid block in which unilateral peripheral femoral neuropathy occurred postoperatively. All were in the lithotomy position with swing stirrups, for over two and one-half hours. This most unphysiological position resulted in the exaggerated abduction and external rotation at the hip, leading to kinking and twisting of the femoral nerve beneath the tough inguinal ligament and thus producing ischaemia of the nerve trunk followed by loss of function. The overall prognosis is excellent; recovery starts within four weeks and is complete by eight to ten weeks. The complication is easily preventable by limiting the abduction of thigh and external rotation at the hip in the lithotomy position, particularly when the operation is expected to last more than one and one-half hours.

\section{Acknowledgement}

We are grateful to Dr. A.M. Vare, Dean, and Mr. Badve, Librarian, Medical College and Hospital, Aurangabad, for allowing us to utilize literature freely.

\section{References}

1 Roblee MA. Femoral Neuropathy from the lithotomy position; Case Repon and new leg holder for prevention. Am J Obstet Gynecal 1967; 97: 871-3.

2 Rosenblum J. Femoral Neuropathy-Neurological complications of Hysterectomy. JAMA 1966; 195 409-14.

3 Vosburgh LF, Finn WF. Femoral Nerve impairment subsequent to hysterectomy. Am J Obstet Gynecol 1961; 82: 931-4.

4 Klings GN. Injury to Femoral Nerve during pelvic operation: Report of Three cases. Obstet Gynecol $1965 ; 25: 619-23$.

\section{Résumé}

On rapporte le cas de trois patientes qui, suite a l'hystérectomie vaginale développèrent une neuropathie fémorale unilatérale et solitaire. Elles subirent l'intervention chirurgicale par l'induction analgésique sousarachnoidien en position gynécologique. Les complications causées par les suites de cette position doivent être dues à l'abduction extrême du fémur avec rotation externale de la hanche causant une ischémie du nerf férnoral, le nouant sous le ligament inguinal très résistant. Le pronostic s"avéra excellent avec guérison complète suivant les huit à dix semaines. On évite les complications en utilisant des supports latéraux pour la cuisse afin de limiter le degré d'abduction. 